village life in modern thailand 


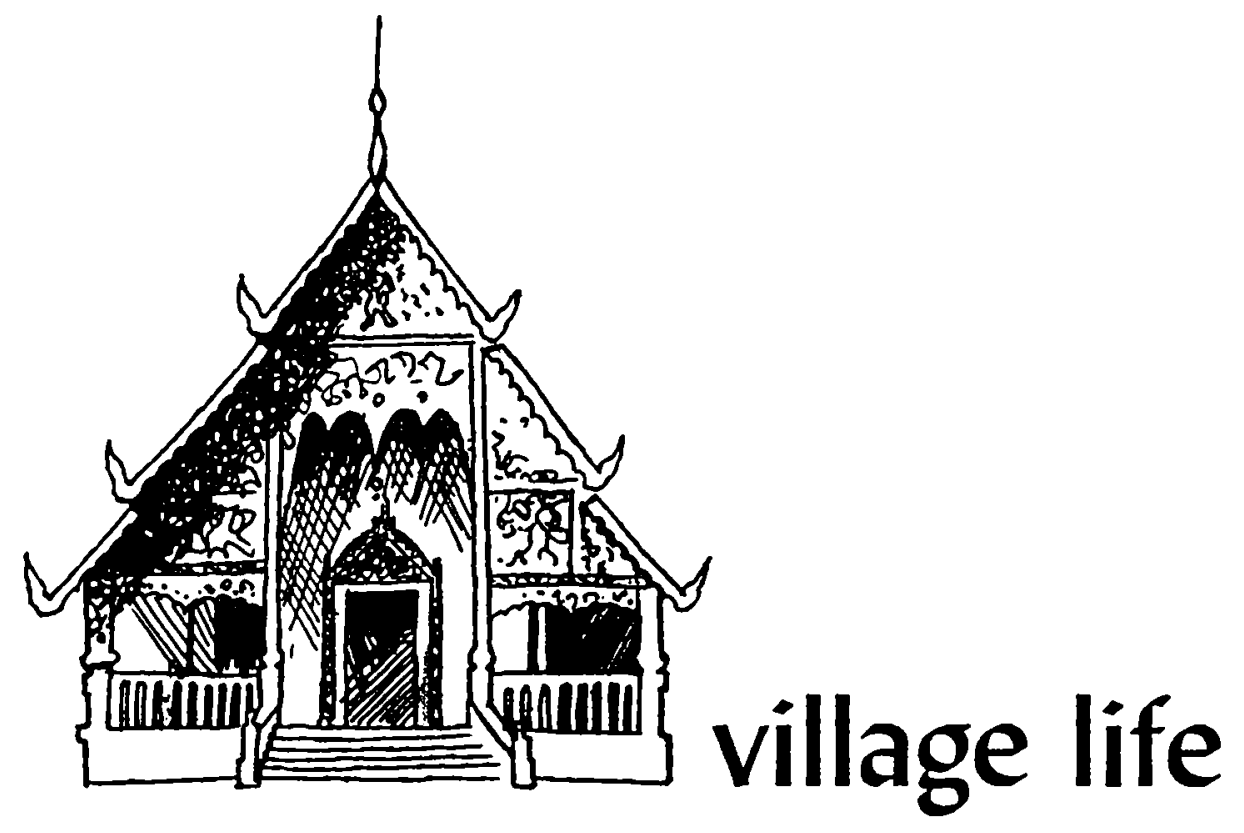

UNIVERSITY OF CALIFORNIA PRESS 
Institute of

East Asiatic Studies

University of California

\section{in modern thailand}

Jobn E. deYoung

BERKELEY AND LOS ANGELES: 1963 
University of California Press

Berkeley and Los Angeles

California

Cambridge University Press

London, England

Library of Congress Catalog Card Number: 55-9979

Copyright, 1955, by

The Regents of the University of California

Third printing, 1963

Manufactured in the United States of America

Designed by Marion Jackson 